\title{
Laboratory Study on Improving Recovery of Ultra-Heavy Oil Using High-Temperature- Resistant Foam
}

\author{
Chunzhi WANG, Zhaomin LI*, Xiaoheng GENG, Yuhao LI, Hongjun HUO, Hongkun ZHANG, Haiying GUO
}

\begin{abstract}
After multiple rounds of steam huff-and-puff processes, an ultra-heavy oil reservoir is prone to excessive steam injection pressure, large heat loss, small sweep range of steam, and steam channeling, thus severely affecting the effective utilization of the oil reservoir. To solve these problems, one-dimensional and three-dimensional (3D) physical simulation tools were used to study the plugging performance of high-temperature composite foams by adding tanning extract and alkali lignin under the influence of some factors such as the reservoir temperature, salinity of formation water, and injection methods. The ultra-heavy oil used in the experiment comes from Shengli Oilfield. Under the condition of surface degassing, the viscosity of ultra-heavy oil could reach $145169 \mathrm{mPa} \cdot \mathrm{s}$ at $60^{\circ} \mathrm{C}$. The experimental results show that the foam can produce a synergistic effect with both gel systems, indicating that the gel increases the stability of the foam. The foam can transfer more gel into the high-permeability formation, which can efficiently control the foam. The 3D physical simulation experiments indicated that both the systems enhance the recovery of heavy oil reservoir and reduce its moisture content significantly using steam injection. The method involving tannin extract foam and steam injection increased the recovery by $20 \%$ compared to the foam involving only steam injection. The method involving alkali lignin foam and steam injection increased the recovery by $\sim 11 \%$.
\end{abstract}

Keywords: alkali lignin; nitrogen foam; super extra-heavy oil; tannin; thermal recovery

\section{INTRODUCTION}

Thermal recovery is the most effective technique to improve the recovery of heavy and ultra-heavy oil, mainly including steam huff-and-puff, steam flooding, hot-water flooding, and in-situ combustion [1-5]. During the steam injection, however, because of the heterogeneity of ultraheavy oil reservoir and the opposite mobility between the steam and heavy oil [6-8], the steam gravity overrides other factors $[9,10]$, and the steam crossflows in the reservoir, resulting in a nonuniform distribution of the steam entry profile and reduction in the steam's utilization [11, 12]. Thus, it is difficult to achieve a better utilization of the oil reservoir.

The international studies have shown that the injection of steam into a high-temperature foam effectively plugs the high-permeability reservoir and forms large pores in the oil reservoir, thus increasing the sweep and displacement efficiencies of steam injection [13]. By adding hightemperature foaming agents and nitrogen, foam is produced in the pores of reservoir, and the high-strength foam rapidly decreases the percolation capability of gas phase [14]. It effectively plugs the high-permeability reservoir and large pores; inhibits the flow of steam into the high-permeability reservoir, layer, and zone; steers the steam into non displacement zone such as lowpermeability reservoir, layer, and zone; increases the displacement volume, improves the sweep area, and improves oil recovery from reservoir $[15,16]$.

World has a large number of heavy oil resources, and now massive heavy oil reservoirs have been discovered in China, Canada and Latin America oilfields. Abundant of heavy oil reservoirs are buried deeply, and have thin reservoir high oil viscosity and poor mobility [17-20]. Currently, when the oil viscosity exceeds $100000 \mathrm{mPa} \cdot \mathrm{s}$, conventional steam huff and puff has inefficient economic benefits. Since the HDCS-enhanced oil recovery technique has been effectively implemented in 2008 , the recent cycle of huff-and-puff in the Zheng 411 block of Shengli Oilfield was generally over six. After several rounds of huff-andpuff, the oil recovery degree of near-wellbore zones is high, whereas a lot of oil remains between wells. The reduction extent of reservoir pressure is large, and the drainage period is long, resulting in a worse multi component composite huff-and-puff with a cumulative oil/steam ratio of only 0.27 . Considering the above problems, this study was carried out for enhancing the thermal recovery and efficiency of heavy oil using a high-temperature foam, focusing on the high-temperature composite foam that can be used at $300^{\circ} \mathrm{C}$ by studying its influencing factors.

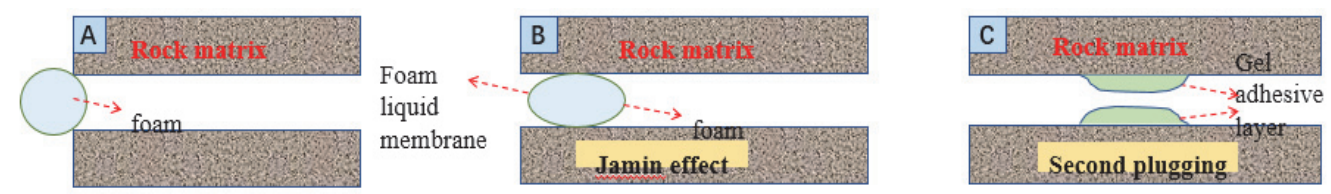

Figure 1 Secondary plugging process of high-temperature composite foams for pore throat

The two high-temperature composite foam control systems have a similar plugging mechanism: The selective plugging is performed by using the difference between the interlaminar and internal permeabilities of the layer of steam injection well, as shown in Figs. 1A and 1B. Using the selection of foam fluid in the reservoir, the foam will preferentially access the steam absorption reservoir with good permeability and a relatively high absorption amount. When the foams enter the reservoir, an additional resistance occurs between the foam and pore throat, finally producing the Jamin effect that plugs the larger pore throat. This is the "first plugging" process after the foams enter the reservoir [21, 22]. As shown in Fig. 1C, with increasing amount of injected steam, the temperature of oil reservoir has gradually increased. The tannin extract or alkali lignin complex that forms the foam liquid membrane originally can react and form a gel at a high temperature when the foam collapses. The gel substance adheres to the wall of 
the pore throat, thus decreasing the diameter of the pore throat and resulting in a narrower path. This increases the percolation resistance between the injected steam and reservoir with relatively high steam absorption. The procedure adjusts the contradictions between the steam entry profile of steam injection wells and the deep section of the reservoir. This is the "the second plugging" of the foam entering into the reservoir, thus improving the utilization ratio of injected steam and recovery of crude oil [15].

\section{EXPERIMENTAL SECTIONS}

\subsection{Chemicals and Preparation of Plugging Solution}

Core barrel heating jacket: core barrel (length: $60 \mathrm{~cm}$, diameter: $2.54 \mathrm{~cm}$ ); steam generator; foam generator; multi component thermal fluid displacement facility for oil reservoir; FYXD03 25/400 reactor that is resistant to high temperature and aging; oven for maintaining a constant temperature. The used chemicals were modified tannin extract, alkali lignin, nitrogen, formaldehyde (37-40\% mass concentration), catechol, sodium chloride, anhydrous calcium chloride; high-temperature foaming agent $\mathrm{HY}$ $\mathrm{GW}$; glass test tube $(100 \mathrm{~mL})$; electronic balance; measuring cylinder $(100 \mathrm{~mL})$.

The high-temperature plugging solution was prepared according to the following formula (mass\%). The tannin foam plugging system was prepared using a tannin extract $(6.0 \%)$, a mixture of formaldehyde and phenol $(4.0 \%)$ as the crosslinking agent, high-temperature foaming agent HY-GW (3\%), and deionized water. The plugging solution was injected with nitrogen at a gas-liquid ratio of 1:1 and a rate of $2 \mathrm{~mL} / \mathrm{min}$. The tannin foam was generated using a foam generator. The $\mathrm{pH}$ of the plugging solution was adjusted to 8-10.

The alkali lignin foam plugging system was prepared from a mixture of alkali lignin $(6.0 \%)$, a mixture of formaldehyde and phenol $(4.0 \%)$ as the crosslinking agent, HY-GW (3\%), and deionized water. The plugging solution was injected with nitrogen at a gas-liquid ratio of 1:1 and a rate of $2 \mathrm{~mL} / \mathrm{min}$. The alkali lignin foam was generated using a foam generator. The $\mathrm{pH}$ of the plugging solution was adjusted to 8 .

\subsection{Static Performance of Plugging System 2.2.1 Effect of Temperature on Foam Performance}

The foaming solutions of nitrogen, tannin extract, and alkali lignin systems were prepared according to a certain proportion. The foams were first placed into an aging vessel resistant to high temperature and then placed in a constant-temperature oven at a given constant temperature for $1 \mathrm{~h}$. After the heating treatment, the solutions were removed to measure their half-lives, foam volumes, foaming abilities (Fig. 2), and half-lives (see Tab. 1) of foams were measured at $100,150,200,250{ }^{\circ} \mathrm{C}$ and atmospheric pressure (Figure 2) at 100, 150, 200, and 250 ${ }^{\circ} \mathrm{C}$. Fig. 2 shows that when the temperature was below 200 ${ }^{\circ} \mathrm{C}$, it had little difference in the foamability between two foams. However, when the temperature was higher than $200{ }^{\circ} \mathrm{C}$, the foamability of the alkali lignin composite system was less than that of the conventional nitrogen system because the alkali lignin above $200{ }^{\circ} \mathrm{C}$ can easily form a partial precipitation. When the temperature reached $300{ }^{\circ} \mathrm{C}$, the foaming agent completely lost its foamability. Therefore, the foams could not generate foam, and their half-lives were $0 \mathrm{~min}$. At this time, the plugging effect mainly relies on the gel, but at a high temperature $<300{ }^{\circ} \mathrm{C}$, the half-lives of the tannin foam and alkaline lignin were much higher than that of the nitrogen foam, which indicated that the composite system has better performance in stabilizing the foam than the conventional nitrogen system.

Table 1 Half-lives of different foams at high temperatures

\begin{tabular}{|l|c|c|c|c|}
\hline \multicolumn{1}{|c|}{ Temperature $\left({ }^{\circ} \mathrm{C}\right)$} & 100 & 150 & 200 & 250 \\
\hline Half-life of nitrogen foam (s) & 352 & 343 & 361 & 377 \\
\hline Half-life of tannin extract foam (min) & 86 & 94 & 119 & 51 \\
\hline Half-life of lignin foam (min) & 83 & 91 & 107 & 43 \\
\hline
\end{tabular}

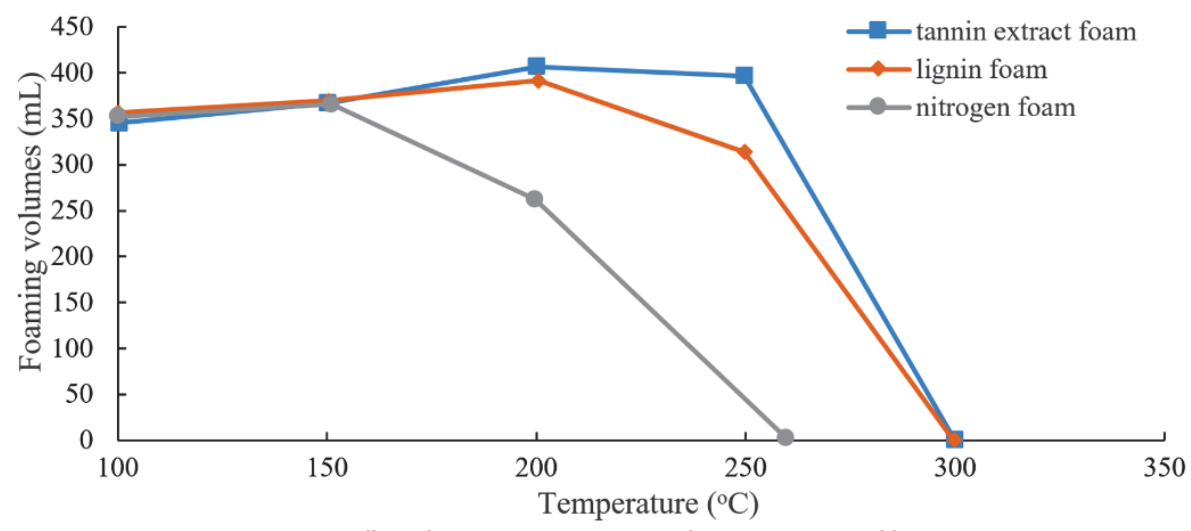

Figure 2 Effect of high temperature on the foaming volumes of foams

\subsubsection{Effect of Salinity on the Gelation Performance of Foam}

The $\mathrm{Na}^{+}$and $\mathrm{Ca}^{2+}$ ions in reservoir water significantly increase the gelation speed of tannin extract system. Because the tannin solution is a colloidal solution with a low molecular weight, the addition of an electrolyte can compress the electrical double layer around the surface of colloidal particles [16]. Because of a higher amount of $\mathrm{Na}^{+}$ and $\mathrm{Ca}^{2+}$ ions in the reservoir and bottom fluid, the effect of salinity on the system should be investigated to apply the plugging foam in oil reservoir with a higher salinity. We investigated the effects of $\mathrm{Na}^{+}$and $\mathrm{Ca}^{2+}$ ions on the performance of the plugging agent. Their gelation strengths were measured by the breakthrough vacuum test. 


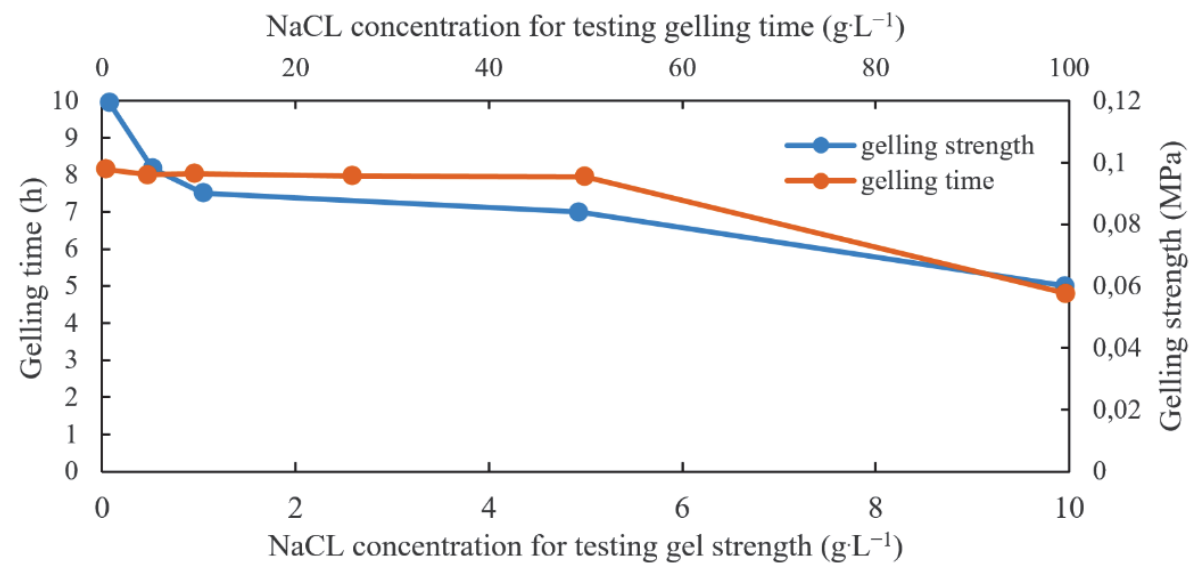

Figure 3 Effect of $\mathrm{NaCl}$ on the gelation time and strength of tannin extract system

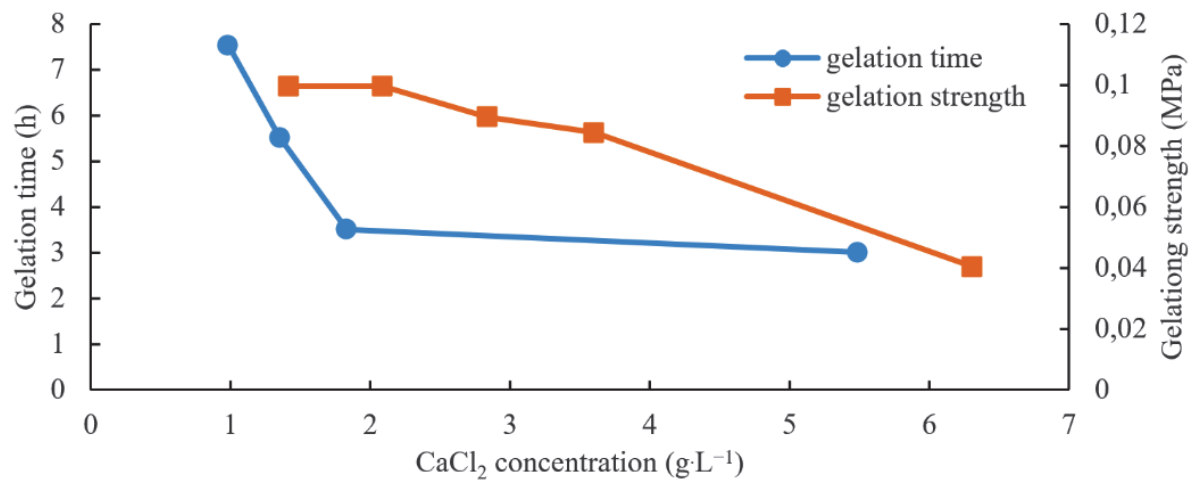

Figure $4 \mathrm{Effect}$ of $\mathrm{CaCl}_{2}$ on the gelation time and strength of tannin extract system

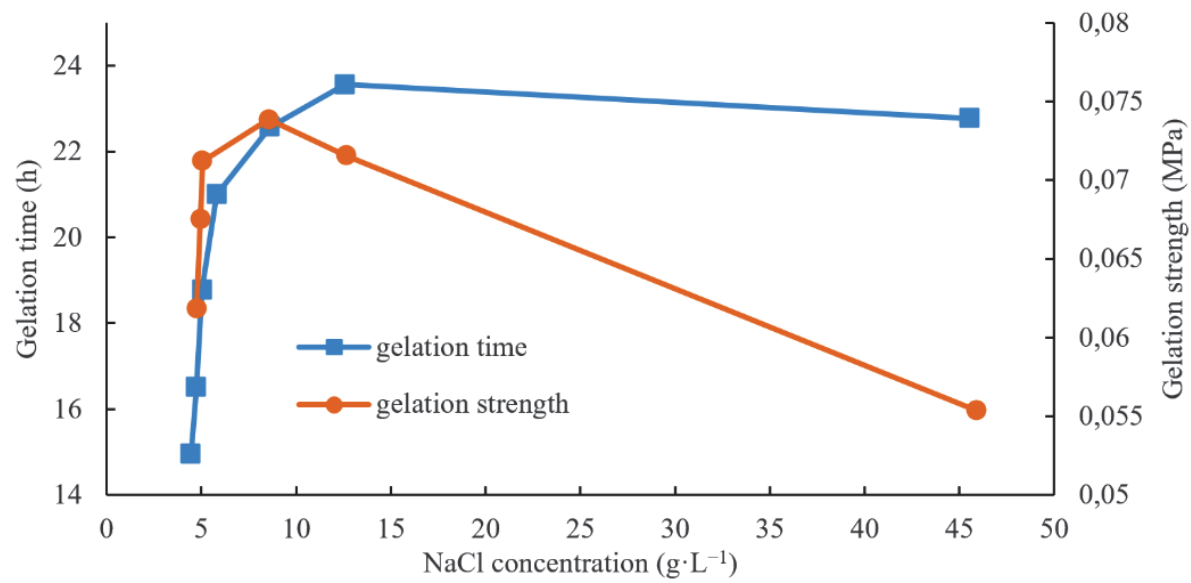

Figure $5 \mathrm{Effect}$ of $\mathrm{NaCl}$ on the gelation time and strength of alkali lignin system

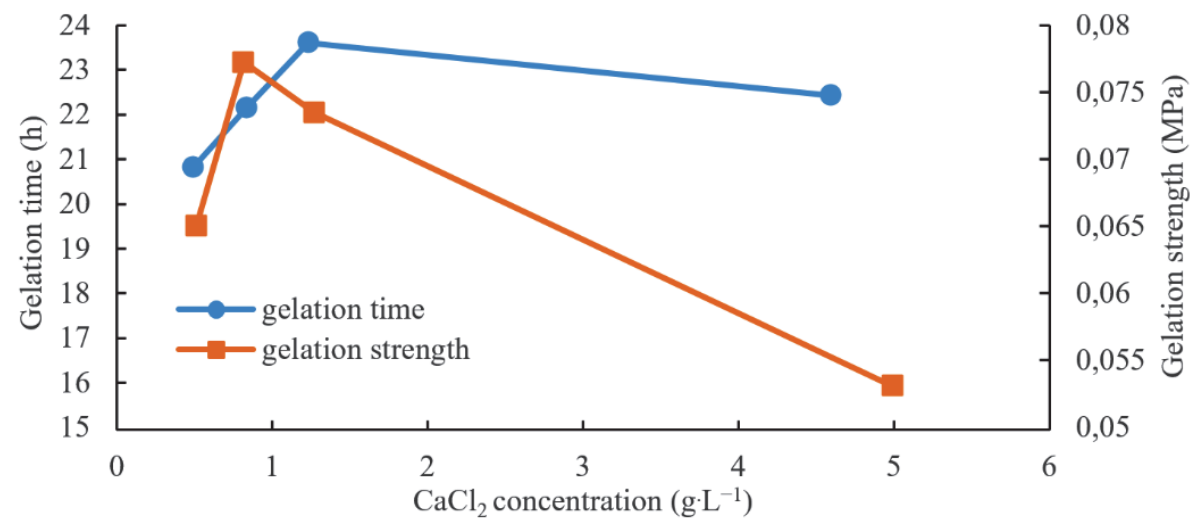

Figure $6 \mathrm{Effect}$ of $\mathrm{CaCl}_{2}$ on the gelation time and strength of alkali lignin system

As a result of the divalent metal ions having a much stronger ability for compressing an electrical double layer on the surface of colloidal particles than monovalent metal ions, Figs. 4 and 5 show that the shortening effect of $\mathrm{Ca}^{2+}$ ions on the gelatin time of tannin plugging agent solution was clearer than that of $\mathrm{Na}^{+}$ions. Fig. 3 shows that the 
tanning foam has less susceptibility to $\mathrm{Na}^{+}$ions. Only when the $\mathrm{NaCl}$ concentration exceeds $50 \mathrm{~g} / \mathrm{L}$ the gel did not form. This is because the $\mathrm{Ca}^{2+}$ ions can compress the electrical double layer on the surface of colloidal particles, resulting in crosslinking and even coagulation. Therefore, the gel strength of the tannin extract decreased significantly and no gel was formed, whereas the strength was almost unaffected by the salinity before the concentration. In the solution with a $\mathrm{NaCl}$ concentration of $100 \mathrm{~g} / \mathrm{L}$, the gelling strength still reached $\sim 0.06 \mathrm{MPa}$. When the $\mathrm{NaCl}$ concentration was $>100 \mathrm{~g} / \mathrm{L}$, the water solubility of the tannin extract decreased. A slight insoluble substance appeared, and the color of the gel changed from reddishbrown to bright red.

Figs. 5 and 6 show that when the $\mathrm{NaCl}$ concentration was $<9000 \mathrm{~g} / \mathrm{L}$, the gelation time and jelly strength showed a higher growth rate with the increase in $\mathrm{NaCl}$ mass fraction. When the salinity continued to increase, the variation in the salinity had almost no influence on the gelation time, whereas the gel strength gradually decreased.
However, with the increase in $\mathrm{CaCl}_{2}$ concentration, both the gel time and strength first increased and then decreased. When the concentration of $\mathrm{CaCl}_{2}$ was higher than $5 \mathrm{~g} / \mathrm{L}$, the system formed a gel.

\subsection{Effect of High Temperature on the Plugging Performance of System in a Porous Medium 2.3.1 Experimental Facility and Steps}

By testing the variation of resistance in a onedimensional (1D) tubular model, the variation in the plugging performance of the foams at high temperatures of $250{ }^{\circ} \mathrm{C}$ and $300{ }^{\circ} \mathrm{C}$ can be determined, and the effect of high temperature on the plugging efficiency of the foam can be studied. The residual resistance factor can be measured through the subsequent water flooding.

Multifunction flooding simulation system under reservoir conditions; core tube heating mantle; core tube (length: $60 \mathrm{~cm}$, diameter: $2.54 \mathrm{~cm}$ ); tannin extract foam; alkali lignin foam; and HY-GW foaming agent.

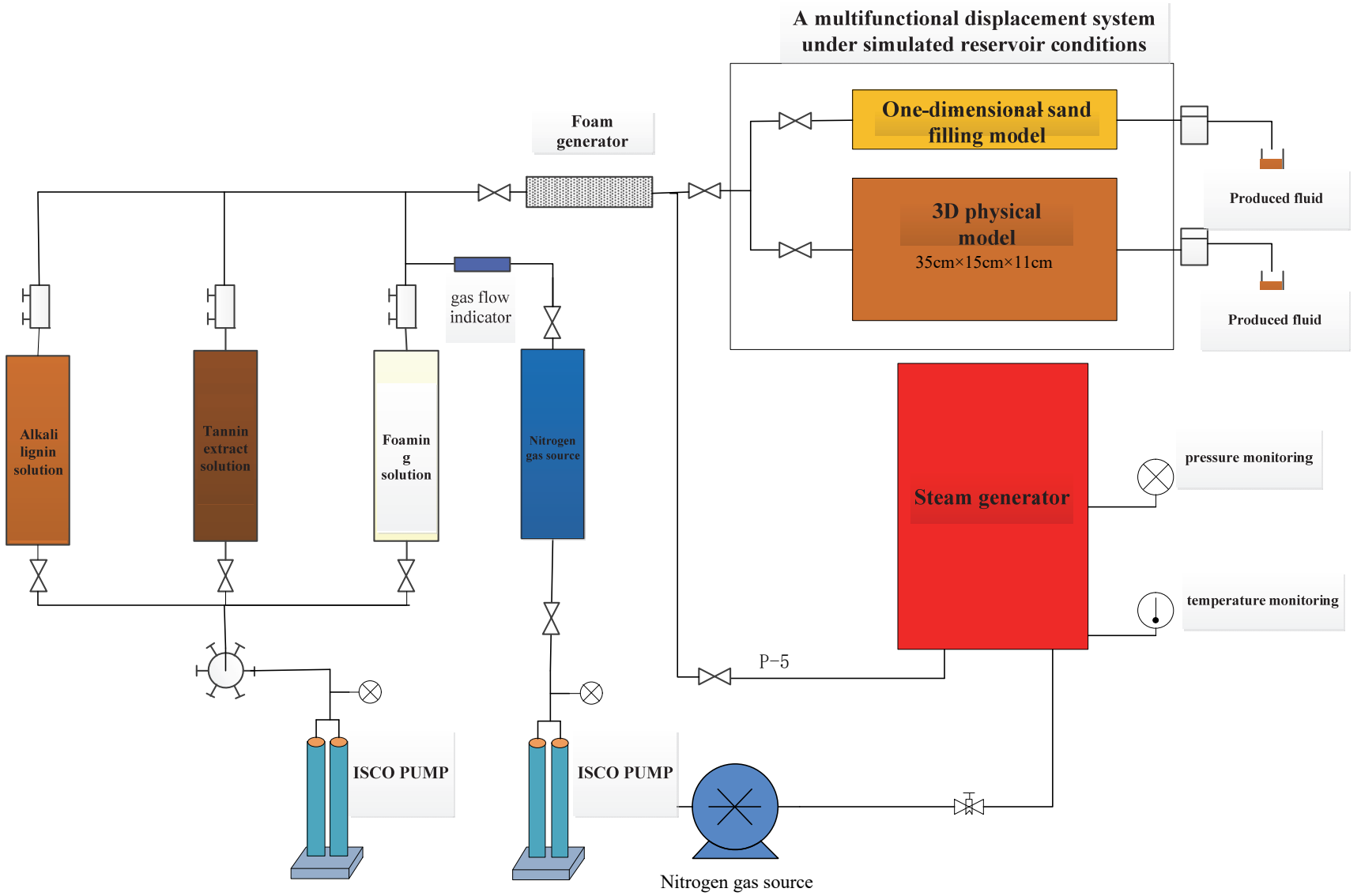

Figure 7 Flow chart of the experiment for evaluating the plugging performance and enhanced recovery of high-temperature-resistant composite foam

As shown in Fig. 7, the quartz sand was filled into the core tube according to a certain proportion for preparing the sand-filling core model. The core permeability was measured by gas. After the dry weight was obtained, the sand-filling core model was evacuated for $4 \mathrm{~h}$, and water was absorbed to reach the saturated state. The core permeability was measured by water. The pressure difference $p_{1}$ was recorded by measuring and recording the multifunction flooding simulation system with a flow rate of $2 \mathrm{~mL} / \mathrm{min}$. The composite foam was injected at a rate of $2 \mathrm{~mL} / \mathrm{min}$. The pressure difference $p_{2}$ between the two ends of the core tube was recorded, where the tannin concentration was $6 \%$, and the backpressure was $1 \mathrm{MPa}$. When the injection pressure was stable and the pump was stopped, the core tube temperature was set at $90{ }^{\circ} \mathrm{C}$ and maintained for $24 \mathrm{~h}$ for gelation. The temperature of the core tube was adjusted to a certain temperature (250 and $300{ }^{\circ} \mathrm{C}$ ), and hot-water flooding was performed at a rate of $2 \mathrm{~mL} / \mathrm{min}$. Then, the breakthrough pressure gradients were measured by using the calculation formula for resistance factor. The resistance factors of different composite foams 
at different temperatures were obtained and could be expressed as Eq. (1).

$$
P_{\mathrm{F}}=\frac{p_{2}}{p_{1}}
$$

where $P_{\mathrm{F}}$ is the foam resistance factor, $p_{1}$ is the differential pressure during water injection, $p_{2}$ the differential pressure during foam injection.

\subsubsection{Comparison and Assessment of the Plugging Performance of Composite Foams at Different Temperatures}

During the entire displacement experiment, the observed effluent liquid was mainly the foam. After several rounds of flushing, the tannin extract was flushed out. Therefore, the plugging procedure of tannin extract can be divided into two stages. First, the foam with a smaller viscous force was flushed out by steam, while the tannin gel still adhered to the pore wall. After flushing the foam, the tannin extract filled the vacancy of pores and formed a secondary plugging, thus improving the plugging ability of the tannin extract foam and the performance that is resistant to flushing.

Fig. 8 shows that after some rounds of steam flushing, both the residual resistance factors of tannin foam and tannin systems concentrated in the range 150-350. The existence of foam in the first half-plugging stage of tannin extract system played a significant role. After several rounds of steam flushing, the residual tannin extract in the core still acted as plugging agent, causing a strong plugging ability in the core.

A comparison of the resistance factor and breakthrough pressure gradient of the tannin extract and alkali lignin plugging systems shown in Figs. 8 and 9, and Tab. 2 indicate that the breakthrough pressure gradient of alkali lignin foam decreased more rapidly. This is because at $300{ }^{\circ} \mathrm{C}$, the foam generated in the alkali lignin system had a lower stability than the foam in the tannin extract system, and the foam collapsed very rapidly at high temperatures, changing the overall performance of the foam. Although the residual system still played a plugging role, its performance was worse than that of the tannin extract system at $300{ }^{\circ} \mathrm{C}$; however, the performance of the alkali lignin foam at $250{ }^{\circ} \mathrm{C}$ was close to that of the tannin extract system at the same temperature.

Table 2 Performance of high-temperature composite foam plugging agent at a high temperature

\begin{tabular}{|c|c|c|c|c|c|}
\hline Types & $\begin{array}{c}\text { Temperature } \\
\left({ }^{\circ} \mathrm{C}\right)\end{array}$ & $\begin{array}{l}\text { Breakthrough pressure } \\
\text { gradient }(\mathrm{MPa} / \mathrm{m})\end{array}$ & $\begin{array}{c}\text { Core permeability before } \\
\text { plugging } \\
\left(\mathrm{K} / 10^{-3} \mu \mathrm{m}^{2}\right)\end{array}$ & $\begin{array}{c}\text { Core permeability after } \\
\text { plugging } \\
\left(\mathrm{K} / 10^{-3} \mu \mathrm{m}^{2}\right)\end{array}$ & $\begin{array}{l}\text { Plugging } \\
\text { percent } \\
(\%)\end{array}$ \\
\hline \multirow{2}{*}{ Tannin extract foam } & 250 & 25.5 & 1842 & 12.35 & 99.32 \\
\hline & 300 & 12.3 & 1867 & 40.85 & 97.81 \\
\hline \multirow{2}{*}{ Alkali lignin foam } & 250 & 20.7 & 1812 & 15.44 & 99.14 \\
\hline & 300 & 10.17 & 1796 & 58.35 & 96.75 \\
\hline
\end{tabular}

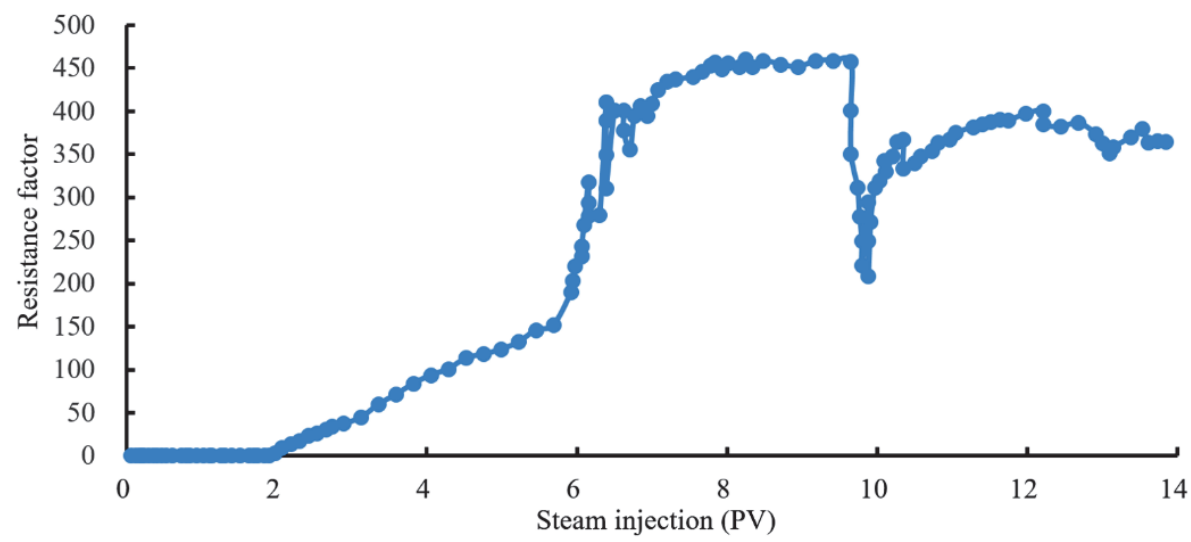

Relationship between the resistance factor and injected amount of tannin extract foam at $250{ }^{\circ} \mathrm{C}$

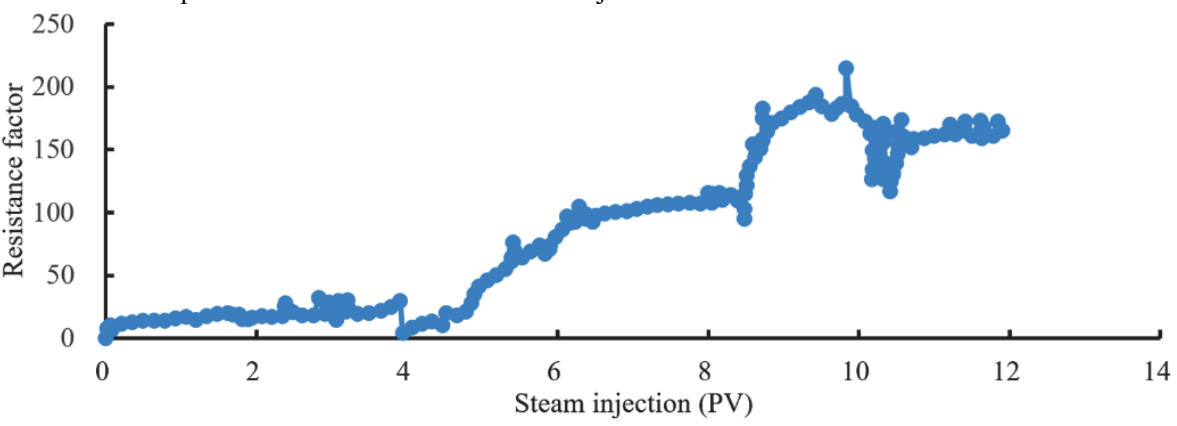

Relationship between the resistance factor and injected amount of tannin extract foam at $300{ }^{\circ} \mathrm{C}$ Figure 8 Relationship between the resistance factor and injected amount of tannin extract foam plugging agent at different temperatures 


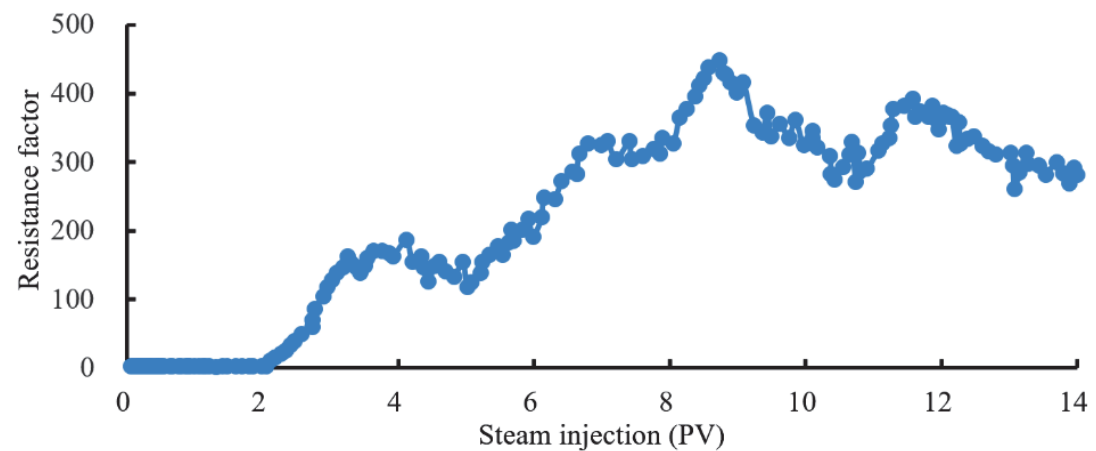

Relationship between the resistance factor and injected amount of alkali lignin foam at $250{ }^{\circ} \mathrm{C}$

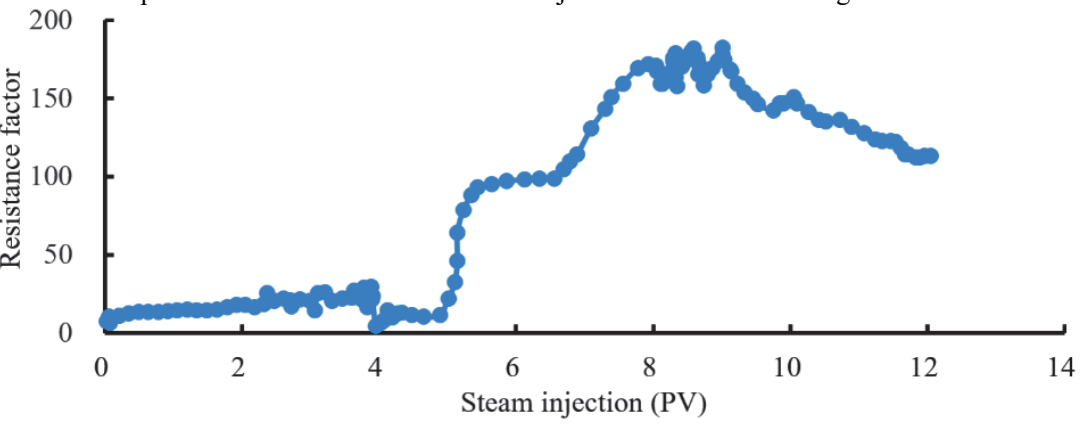

Relationship between the resistance factor and injected amount of alkali lignin foam at $300{ }^{\circ} \mathrm{C}$

Figure 9 Relationship between the resistance factor and injected amount of alkali lignin foam plugging agent at different temperatures

3 EFFECT OF HIGH-TEMPERATURE-RESISTANT COMPOSITE FOAM ON THE RECOVERY OF ULTRAHEAVY OIL

\subsection{Plugging Pressure Drop Test for Crude Oil}

The multicomponent thermal fluid displacement facility was used to study the relationship between the saturation level of remaining oil and resistance factor of foam in oil reservoir. The experimental temperature was set at $280{ }^{\circ} \mathrm{C}$, and the experimental core was a $1 \mathrm{D}$ sandfilling model. The saturated crude oil was obtained from the Zheng-411 block of Shengli Oilfield. The relationship between the plugging pressure drop and the saturation level of remaining oil was measured. The analysis of the experimental results shows that when the saturation levels of the remaining oil were higher than $26 \%$ and $32 \%$ for the tannin and alkali lignin foams, respectively, the foams could not achieve a higher plugging pressure difference. When the saturation levels of the remaining oil were less than $26 \%$ and $32 \%$ for the tannin and alkali lignin foams, respectively, the plugging pressure drops of the two systems increased significantly, indicating that the selective plugging of the composite plugging system is particularly critical for the development of heavy-oil reservoir in the later stage of multiple rounds of huff-andpuff. At this time, the remaining oil is distributed in the low permeability zone. The foam forms plugging in the highpermeability area with a lower saturation level of the remaining oil, and the residual liquid enters and displaces the low-permeability area with a higher saturation level of the remaining oil, thus improving the recovery.

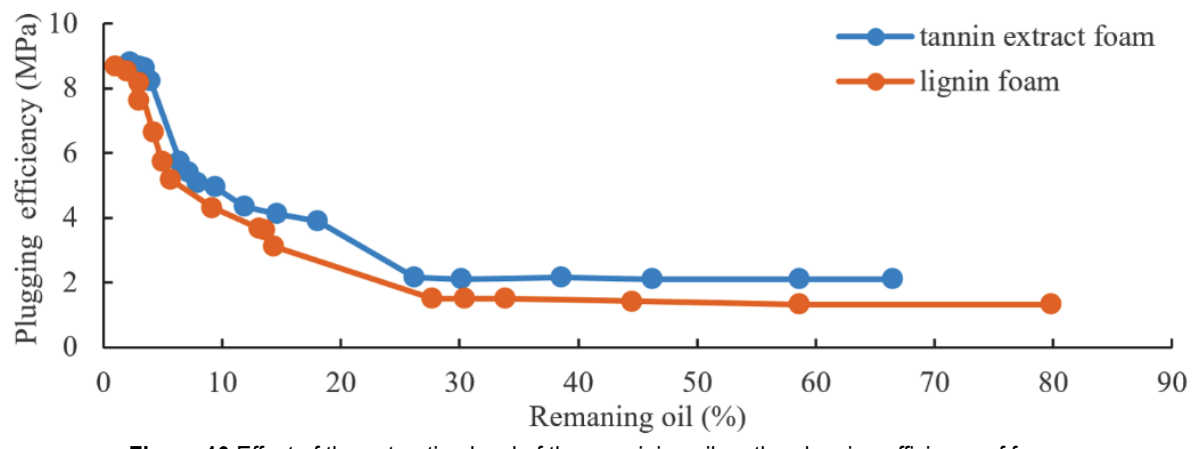

Figure 10 Effect of the saturation level of the remaining oil on the plugging efficiency of foams

3.2 Effect of High-Temperature-Resistant Composite Foam on the Recovery of Heavy Oil

\subsubsection{Effect of High-Temperature-Resistant Composite} Foam on the Displacement Efficiency of Heavy Oil

We studied the displacement efficiencies of the foams using three sets of 1D tubular core models. The simulation core was prepared using the sand obtained from the reservoir of Zheng 411 block. The core permeability was $1755 \times 10^{-3} \mu \mathrm{m}^{2}$. The saturated heavy oil was obtained from the Zheng 411 block of Shengli Wangzhuan Oilfield. The core temperature was set at $68{ }^{\circ} \mathrm{C}$. First, the steam with 5 $\mathrm{PV}$ and $250^{\circ} \mathrm{C}$ was injected for the displacement, and then the 3PV high-temperature composite systems with steam were injected. The experimental results are shown in Fig. 11. 


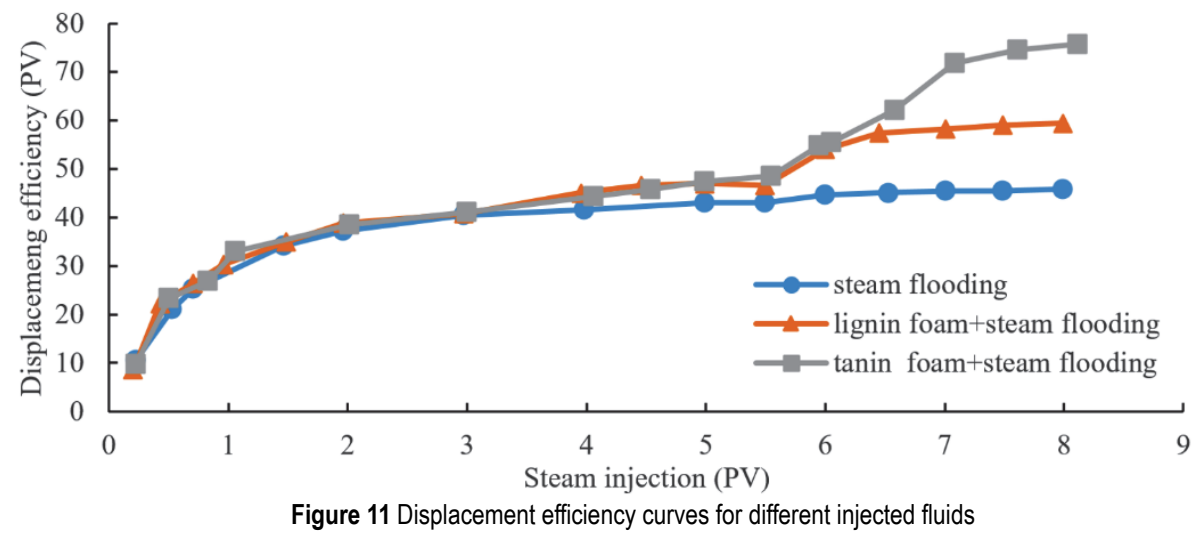

Fig. 11 shows that 5 PV steam was injected first in three groups of core displacement test. During the stage, the recovery amounts are different because of different cores, whereas the final recoveries were similar. The recoveries of the tannin extract and alkali lignin foam with steam injection were higher than that of the system with injected steam only, indicating that the high-temperature composite foam can effectively improve the displacement efficiency of the injected steam. Based on the condition that the injection amount of the steam is the same, the final recovery of the tannin extract foam was up to $30 \%$ higher than that of the system with injected steam only.

\subsubsection{Experimental Study on Enhancing the Recovery of Heavy-Oil Reservoir}

The increase in the recovery of heavy-oil reservoirs using the high-temperature foam was studied using a 3D physical model. The internal size of the model was $35 \times 15$ $\times 11 \mathrm{~cm}^{3}$, the simulated reservoir thickness was $5.7 \mathrm{~m}$, and the oil saturation was $87.3 \%$. The viscosity of the stock tank oil was $12 \times 10^{4} \mathrm{mPa}$ at reservoir temperature. The horizontal wells for injecting gas and producing oil had a distance $150 \mathrm{~m}$. As shown in Fig. 7, the path of 1D core experiment was closed, whereas the path of 3D model was opened. The model was adjusted and placed statically, the heating was switched off, the model was cooled to below $60{ }^{\circ} \mathrm{C}$, and then the heating was performed until the temperature of oil reservoir, $68{ }^{\circ} \mathrm{C}$, was achieved. A $75 \%$ dry steam with a temperature of $280{ }^{\circ} \mathrm{C}$ was injected continuously using production wells into the simulated oil layer at a rate of $7.5 \mathrm{~mL} / \mathrm{min}$, and the injected speed of the foam agent was $1 \mathrm{~mL} / \mathrm{min}$. First, the foam with a nitrogen/foam ratio of 1:1 was generated using a foam generator and then injected into a $3 \mathrm{D}$ physical model using steam. The production horizontal wells produced continuously. First, the steam flooding was performed, and then the steam flooding was performed by injecting the tannin and alkali lignin foams. The total volume of the injected fluid was $8 \mathrm{PV}$.

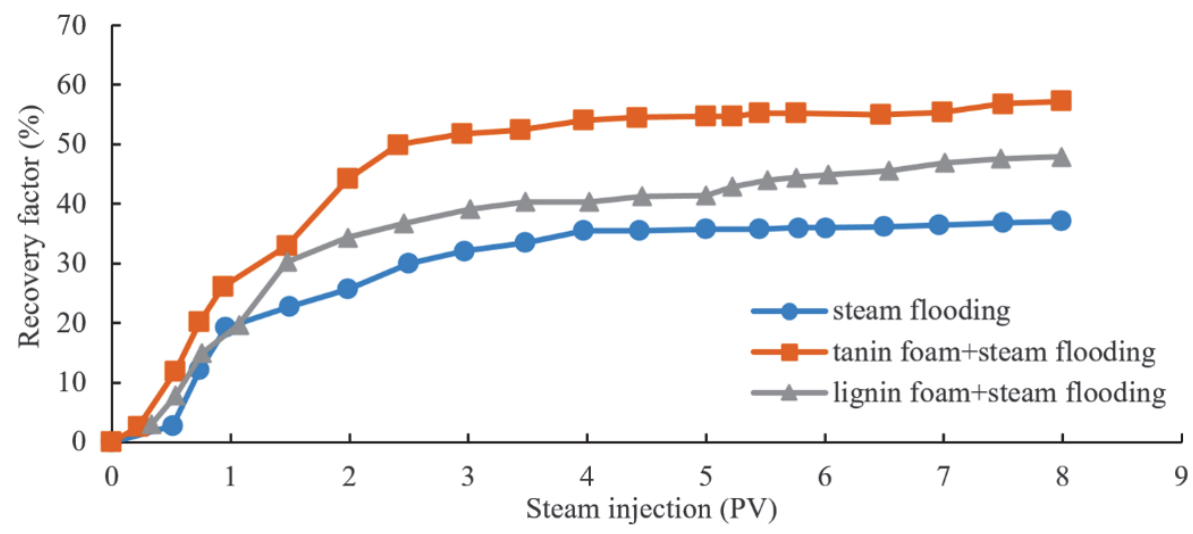

a) Relationship between the injected amount of steam and recovery in different profile control systems

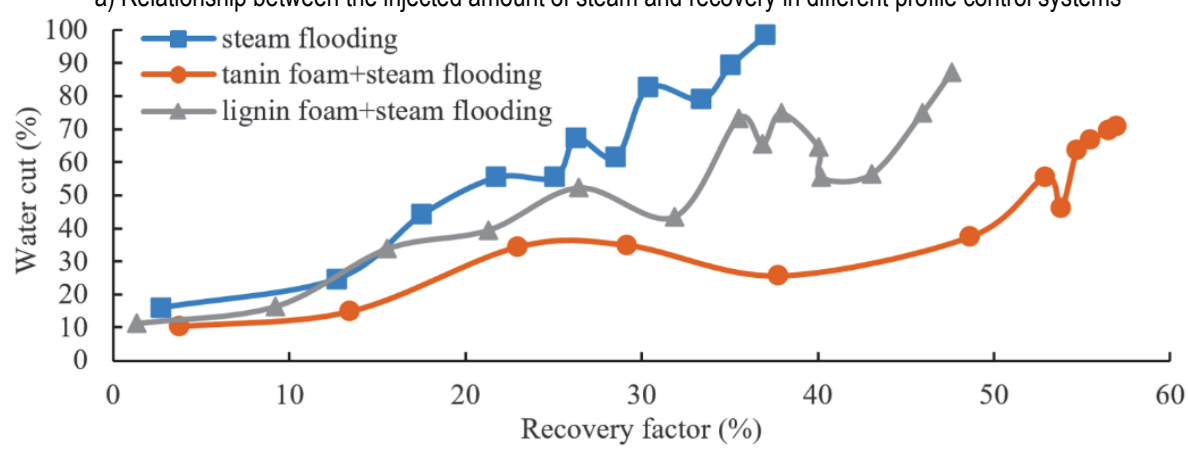

b) Relationship between the recovery and moisture content of the steam flooding in different profile control systems

Figure 12 Recovery and comprehensive moisture content curves of systems for different injected fluids 
Fig. 11 shows that during the pure steam displacement, the recovery reached the limit of $35 \%$ when the injected amount of steam was $\sim 4 \mathrm{PV}$. For the high-temperature composite foam with steam injection, the recovery increased by $28 \%$ and $11 \%$, respectively (Fig. 12a compared to that of the system with only steam displacement). The plugging and profile control effectively reduced the moisture content by using these two foams with steam injection. The moisture content increased rapidly when the recovery approached its limit (Fig. 12a).

Fig. 12b shows that after the profiles of hightemperature composite foams were under control, the recoveries were both higher than that of the horizontal well steam displacement, and the tannin extract foam had the highest recovery, with an increase of about $20 \%$, while the corresponding injection pressure increased as well. The early growth of injection pressure can be attributed to a high viscosity and poor mobility of oil in near-wellbore zones, and the late growth of injection pressure can be attributed to the strong plugging formed by the composite foam in porous media. The injection of nitrogen only can increase the recovery, but the growth was limited. When the nitrogen and foaming agent were injected together, because of the gravity differences, the nitrogen gathered at the top of the rectangular model, playing a role in insulating the heat, maintaining the temperature, increasing the energy, helping to expel and furthermore supplementing the energy of the reservoir, which is an important mechanism for increasing the recovery.

\section{CONCLUSIONS}

The advantage of the high-temperature-resistant composite foam such as high-temperature gel and foam is the stability of foam. Moreover, the added foam carried more gel into the high-permeability reservoir more uniformly, thus significantly improving the performance of the foam and paving the path for a more extensive application. For on-site applications, the loss of foaming agent resulting from the thermal degradation and surface adsorption of rock should be considered, and therefore the dosage of foaming agent should be increased.

The 3D physical simulation experiments for improving the recovery of heavy oil showed that the recoveries of heavy oil increased by both foams with steam injection. Moreover, the moisture content decreased significantly. For example, the tannin extract foam with steam injection had an approximately $20 \%$ higher recovery than by steam injection only, whereas the alkali lignin foam increased the recovery by approximately $11 \%$. This difference is mainly because the stability of alkali lignin foam is lower than that of the tannin extract foam above $250{ }^{\circ} \mathrm{C}$.

\section{Acknowledgements}

This work is supported by the Shandong Provincial Natural Science Foundation (grant number ZR2019PEE046).

\section{REFERENCES}

[1] Nehring, R., Hess, R., \& Kamionski, M. (1983). The Heavy
Oil Resources of the United States. Santa Monica, CA: RAND Corporation. https://www.rand.org/pubs/reports/ R2946.html

[2] Riazi, M. R. (1996). A New Method for Experimental Measurement of Diffusion Coefficients in Reservoir Fluids. J. Pet. Sci. Eng., 14, 235-250. https://doi.org/10.1016/0920-4105(95)00035-6

[3] Des Brisay, C. M. (1989). Pumping Heavy Oils with the Acid of Downhole Oil-in-Water Eulsidicarions. The Journal of Canadian Petroleum Technology, 28(2), 80-84. https://doi.org/10.2118/89-02-05

[4] Li, R. F., Bleu, R. B. L., Liu, S. H., Hirasaki, G. J., \& Miller, C. A. (2008). 20-23 April, Tulsa, Oklahoma.

[5] Fisher, A. W., Fouiser, R. W. S., \& Goodyear, S. G. (2008). 22-25 April, Tulsa, Oklahoma.

[6] Li, Z. Q., Song, X. W., Wang, Q. W., Li, Z., Guo, P., Li, \& X. L. (2009). International Petroleum Technology Conference, 7-9 December, Doha, Qatar.

[7] Mai, A., Bryan, J., Goodarzi, N., \& Kantzas, A. (2009). Journal of Canadian Petroleum Technology 48(3), 27-35. https://doi.org/10.2118/09-03-27

[8] Miller, K. A. (2006). Journal of Canadian Petroleum Technology 45(4), 7-11. https://doi.org/10.2118/06-04-GE

[9] Zhou, G. H., Song, X. L., Wang, Q. W., Guo, P., Li, X. L., \& Li, S. X. (2006). Petroleum Exploration and Development 33(3), 369-373

[10] Chao, H. Q. (2006). Beijing: Petroleum Industry Press, 347351.

[11] Schramm, L. L. (1994). Foams: fundamentals and applications in the petroleum industry, Washington DC: ACS. https://doi.org/10.1021/ba-1994-0242

[12] Raymundo, A., Empis, J., \& Sousa, I. (1998). Journal of Food Engineering, 36(4), 445-452. https://doi.org/10.1016/S0260-8774(98)00063-6

[13] Dickinson, E., Izgi E., \& Colloids, E. (1996). Surfaces A: Physicochemical Engineering Aspects, 113(2), 191-201. https://doi.org/10.1016/0927-7757(96)03647-3

[14] Yen, T. F. (1992). Fuel Sci. Tech. Int., 1(6), 723-733. https://doi.org/10.1080/08843759208916018

[15] Nguyen, Q. P., Zitah, P. L. J., Currie, P. K., \& Rossen, W. R. (2008). 16-19 April, Tulsa, Oklahoma.

[16] Isaacs, E. E., McCarthy, F. C., \& Maunder, J. D. (1998). Spe Reservoir Engineering, 3(2), 565-572. https://doi.org/10.2118/15647-PA

[17] Zhang, Y. P., Hyndman, C. L., \& Maini, B. B. (2000). J. Pet. Sci. Eng., 25, 37-47. https://doi.org/10.1016/S0920-4105(99)00031-5

[18] James, L. A., Chatzis, I., \& Ioannidis, M. A. (2003). Petroleum Society's $5^{\text {th }}$ Canadian International Petroleum Conference 2003, Calgary, Albera, Canada, June, 10-12.

[19] Renner, T. A. (1988). SPE Reservoir Eng. May, 517-523. https://doi.org/10.2118/15391-PA

[20] Chukwunma, F. O. (1983). Thesis, the University of Tulsa, Tulsa, Oklaboma, USA.

[21] Riazi, M. R. (1996). J. Pet. Sci. Eng., 14, 235-250. https://doi.org/10.1016/0920-4105(95)00035-6 Upreti, S. R. (2009). Ind. Eng. Chem. Res., 39, 3 10801087. https://doi.org/10.1021/ie990635a 


\section{Contact information:}

\section{Chunzhi WANG}

Department of Chemical Engineering and Safety,

Binzhou University,

Binzhou, Shandong 256603, China

\section{Zhaomin LI}

Corresponding author

China University of Petroleum,

Qingdao, Shandong 257061, China

E-mail: zhaominlimail@126.com

\section{Xiaoheng GENG}

Department of Chemical Engineering and Safety,

Binzhou University,

Binzhou, Shandong 256603, China

Yuhao LI

Department of Chemical Engineering and Safety,

Binzhou University,

Binzhou, Shandong 256603, China

\section{Hongjun HUO}

Department of Chemical Engineering and Safety,

Binzhou University,

Binzhou, Shandong 256603, China

\section{Hongkun ZHANG}

Department of Chemical Engineering and Safety,

Binzhou University,

Binzhou, Shandong 256603, China

Haiying GUO

Department of Chemical Engineering and Safety,

Binzhou University

Binzhou, Shandong 256603, China 